\title{
Sedimentological evidence for seiching in a swell-dominated headland-bay system: Table Bay, Western Cape, South Africa
}

\author{
Mike Woodborne ${ }^{1} \cdot$ Burg Flemming ${ }^{2}$
}

Received: 12 November 2020 / Accepted: 2 September 2021 / Published online: 18 September 2021

(c) The Author(s) 2021

\begin{abstract}
Table Bay, South Africa, is a typical headland-bay system with a shoreline that can be described by a logarithmic spiral. A peculiarity and unique feature of Table Bay is the juxtaposition of Robben Island opposite its headland. As a consequence, the bathymetry defines an ellipsoidal basin which was postulated to potentially resonate in the form of long-period standing waves (seiches). One aim of this study, therefore, was to investigate whether any evidence for such resonant oscillations could be detected in the geomorphology and sediment distribution patterns. Indeed, the ellipsoidal shape of the basin can be framed by two converging log-spirals with their centres located opposite each other, one off Robben Island and the other on the Cape Town side of the bay. The so-called apex line, which divides the two spirals into equal parts is aligned SW-NE, i.e. more or less parallel to the direction of ocean wave propagation. The distribution patterns of all sedimentary parameters were found to be characterised by a strikingly similar trend to either side of the apex line. This supports the hypothesis that the basin of Table Bay appears to resonate in the form of a mode 1 standing wave, with the node positioned above the apex line in the centre of the bay. The maximum period of such a standing wave was calculated to be around $37 \mathrm{~min}$. The study demonstrates that large-scale sediment distribution patterns can reveal the existence of specific hydrodynamic processes in coastal embayments. It is recommended that this phenomenon be investigated in greater detail aimed at verifying the existence of resonant oscillations in Table Bay and, in the event, at establishing its precise nature and trigger mechanism.
\end{abstract}

\section{Introduction}

Table Bay and the city of Cape Town with its deep-water harbour are located at the southwestern tip of Africa (Fig. 1a). Table Bay has recently received attention in a geological context concerning the rocks exposed on the seafloor (which belong to the Neoproterozoic Malmesbury Group) with respect to the evolution of the western branch of the Pan-African Saldania Belt (for more details, cf. Rowe et al. 2010; MacHutchon et al. 2020). To set a counterpoint to the ancient geology of the region, it would seem both timely and appropriate to also have a look at the more recent geologi$\mathrm{cal} /$ geomorphological context of Table Bay, in specific, its

Burg Flemming

bflemming@senckenberg.de

Mike Woodborne

mike.woodborne@gmail.com

1 Placer Resource Management (Pty) Ltd, Perth, Australia

2 Senckenberg Forschungsinstitut Und Naturmuseum, Frankfurt Suedstrand 40, Wilhelmshaven 26382, Germany present shape and sediment character, neither of which has received previous attention in the international literature.

As evident from Fig. 1b, Table Bay is a typical headland-bay system with a shoreline that curves away from the headland with a progressively opening angle (e.g. Short and Masselink 1999; Jackson and Cooper 2010; Gallop et al. 2020). Krumbein (1944) was the first to suggest that the geometry of such shorelines could be described by logarithmic spirals. This concept was later applied to numerous headland-bay systems worldwide (e.g. Yasso 1965; Bremner and Le Blond 1974; Le Blond 1979; Phillips 1985; Kimberley 1989; Terpstra and Chrzastowski 1992). In South Africa, the log-spiral approach was previously applied to a South African pocket bay along the west coast (Flemming 1977) and several headland-bay shorelines along the south coast (Bremner 1983, 1991), but not to Table Bay.

It is worth noting in this context that Hsu et al. (1987) and Hsu and Evans (1989), after extensive testing, suggested that parabolic fits were superior to log-spiral fits because the latter appeared to be limited with respect to the length of the shorelines to the outer reaches of the headland bays. However, one of the largest systems yet studied in this connection 


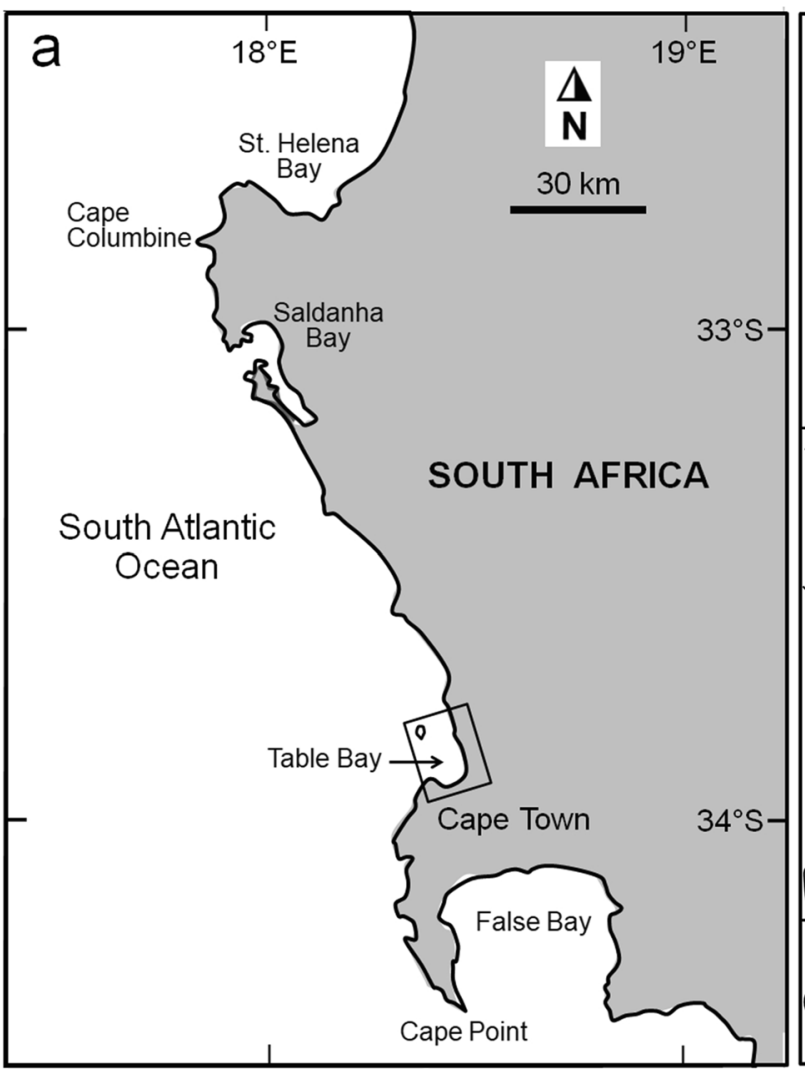

Fig. 1 a Regional locality chart of the South African west coast between St. Helena Bay and the Cape Peninsula. b Blow-up of the study area (Table Bay). The bathymetric contours represent metres

is Algoa Bay, South Africa, where the best fit length of the shoreline amounted to $60 \mathrm{~km}$ (Bremner 1983). Furthermore, Göttisheim and Flemming (2013) showed that both approaches (i.e. log-spiral and parabolic fits) yielded practically identical results for a shoreline length up to $80 \mathrm{~km}$. Beyond this distance, the log-spiral fit began to progressively diverge, whereas the parabolic fit remained accurate for a considerably larger distance. With a shoreline length of only $18.5 \mathrm{~km}$, Table Bay is by comparison a much smaller system, and fitting a log-spiral to its shoreline was therefore considered adequate for the purpose of this study.

Of interest is also that the basins of Table Bay Harbour are notorious for their 'range action' (surging, seiching) in response to specific external forcing conditions (Wilson 1953, 1954, 1976), and which present a constant threat to the safe berthing of ships entering the harbour. In fact, Wilson (1976) postulated that, due to the ellipsoidal bathymetric shape of Table Bay, it could be viewed as a basin prone to resonate in the form of free modal oscillations produced by long-period standing waves (seiches) characterised by either single or multiple nodes. A logical consequence, therefore, was to investigate whether any evidence for such resonant oscillations could below marine chart datum (lowest astronomical low tide) and were extracted from the nautical chart of Table Bay issued by the South African Hydrographic Office

be detected in the geomorphology and, in particular, in the distribution patterns of textural sediment parameters.

Thus, with respect to the issues outlined above, the foremost aims of this study were as follows: (a) to mathematically describe the planimetric shape of the Table Bay shoreline; (b) to present previously unpublished data on the distribution of textural sediment parameters in the bay; and (c) to investigate whether the hypothesis of Wilson (1976) regarding the resonant oscillation potential of the bay could be recognised in the sediment distribution patterns.

\section{Physical setting}

\section{Geomorphological aspects}

Table Bay can be centred on the geographic coordinates of $33^{\circ} 52^{\prime} \mathrm{S} / 18^{\circ} 27^{\prime} \mathrm{E}$. The bathymetry of the bay outlines an ellipsoidal basin between the harbour in the south and the ridge between Robben Island and Blouberg Strand in the north (Fig. 2; adapted from De Wet 2012). When comparing the bathymetry in Fig. 1b with that of Fig. 2, a depth offset in the isobaths is noted. This is explained by the fact that the 
Fig. 2 Bathymetric chart of Table Bay (simplified after de Wet 2012). Depth contours are in metres below mean sea level. Also shown are the locations of sediment samples collected for grain-size analysis (Woodborne 1983)

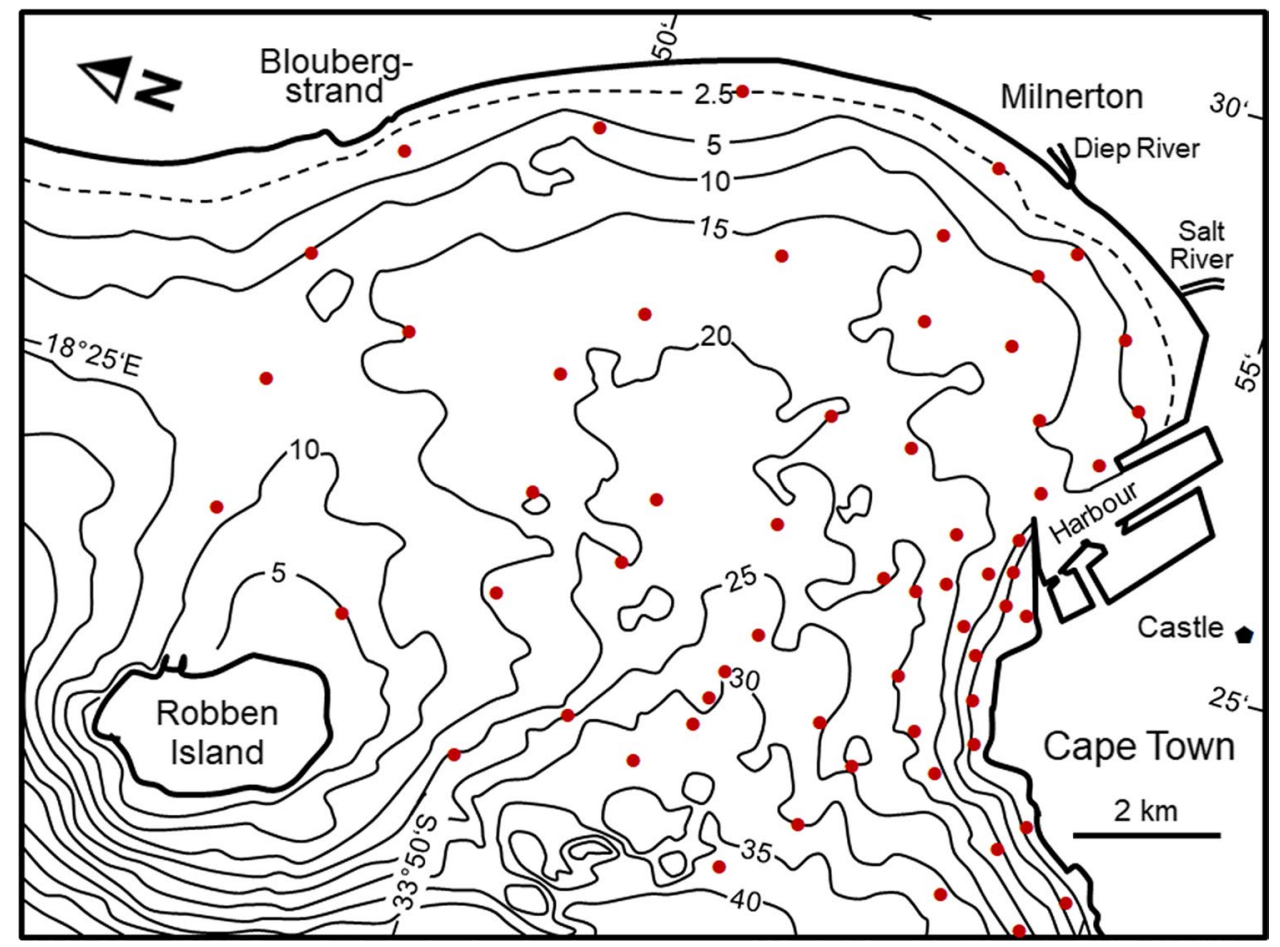

bathymetry in Fig. 1b relates to marine chart zero which, for navigational safety, corresponds to the long-term average of the lowest astronomical tide (extracted from the nautical chart of Table Bay issued by the SA Hydrographic Office), whereas the chart zero in Fig. 2 relates to mean sea level (cf. De Wet 2012) which, more or less, corresponds to the mid-tide level.

A peculiarity and unique feature of Table Bay is the juxtaposition of Robben Island opposite the headland of the bay proper (Mouille Point; cf. Figure 3b). The tombolo-like submarine ridge linking the island with the mainland shore at Blouberg Strand forms the northern boundary of an ellipsoidal basin approximately bounded by the $12 \mathrm{~m}$ isobath (Fig. 2). As pointed out before, the significance of this feature was first recognised by Wilson (1953) in connection with his study of range action (surging, seiching) in the basins of Table Bay harbour (Fig. 3a).

\section{Oceanographic aspects}

The west coast of South Africa is exposed to a severe wave climate dominated by large, long-period ocean swells generated in the distant Southern Ocean southwest of South Africa. Early systematic wave observations and their statistical analyses were conducted by Darbyshire (1963), Darbyshire and Darbyshire (1964) and Darbyshire and Pritchard (1966). They identified two types of long waves, a shorter period type $(0.5-6 \mathrm{~min})$ which they associated with socalled surf beats, and a longer period type ( $>15 \mathrm{~min}$ ) which appeared to correlate with atmospheric (i.e. barometric) pressure fluctuations. This earlier work was continued by
Harris et al. (1972), Shillington and Harris (1978), Shillington (1982, 1984) and Schumann (1983) who recognised that, near the coast, the long-period waves could be described as coastal trapped waves associated with the passage of low pressure systems, especially during the southern winter season (May-September). Based on a permanent waverider buoy installed at $70 \mathrm{~m}$ water depth west of the Cape Peninsula, predominant wave periods were found to range from 8-12 s which, in Table Bay, were associated with significant wave heights of 2-5 m (Fig. 4a) (Rossouw 1989; Seifart 2012; Joubert and van Niekerk 2013). The maximum annual spring tidal range in Table Bay is $1.86 \mathrm{~m}$ (cf. Tide Tables issued by the SA Hydrographic Office; Joubert and van Niekerk 2013). As the tidal wave approaches the coast at almost right angles, the tidal currents along the coast and in Table Bay are relatively weak.

\section{Meteorological aspects}

In contrast to the dominant south-westerly wave incidence, the wind field is dominated by equally consistent southeasterly winds (Fig. 4b; modified after Seifart 2012). As a consequence, aeolian deflation of beaches is a prominent process along the South African west coast and is generally associated with a northward longshore drift of terrigenous sand supplied by local streams (Franceschini et al. 2003). This northward drift is produced by two factors, namely, the oblique incidence of long-period swells approaching the west coast from the southwestern quadrant, and the 
Fig. 3 a Table Bay represented by an idealised elliptical basin prone to seiche motions as conceived by Wilson (1976). b Planimetric shape of the Table Bay shoreline defined by a logarithmic spiral with an indentation ratio of 0.5 . Note the onland continuation of the log-spiral passing close to Cape Town Castle, the land towards Cape Town Harbour having been reclaimed in the late nineteenth century. c Central section of a drawing composed by the British Hydrographer John Seller in 1693 showing Table Bay with Table Mounting in the background ( source: Cape Town Archives). The sketch confirms that Cape Town Castle was originally located close to the shore of the bay
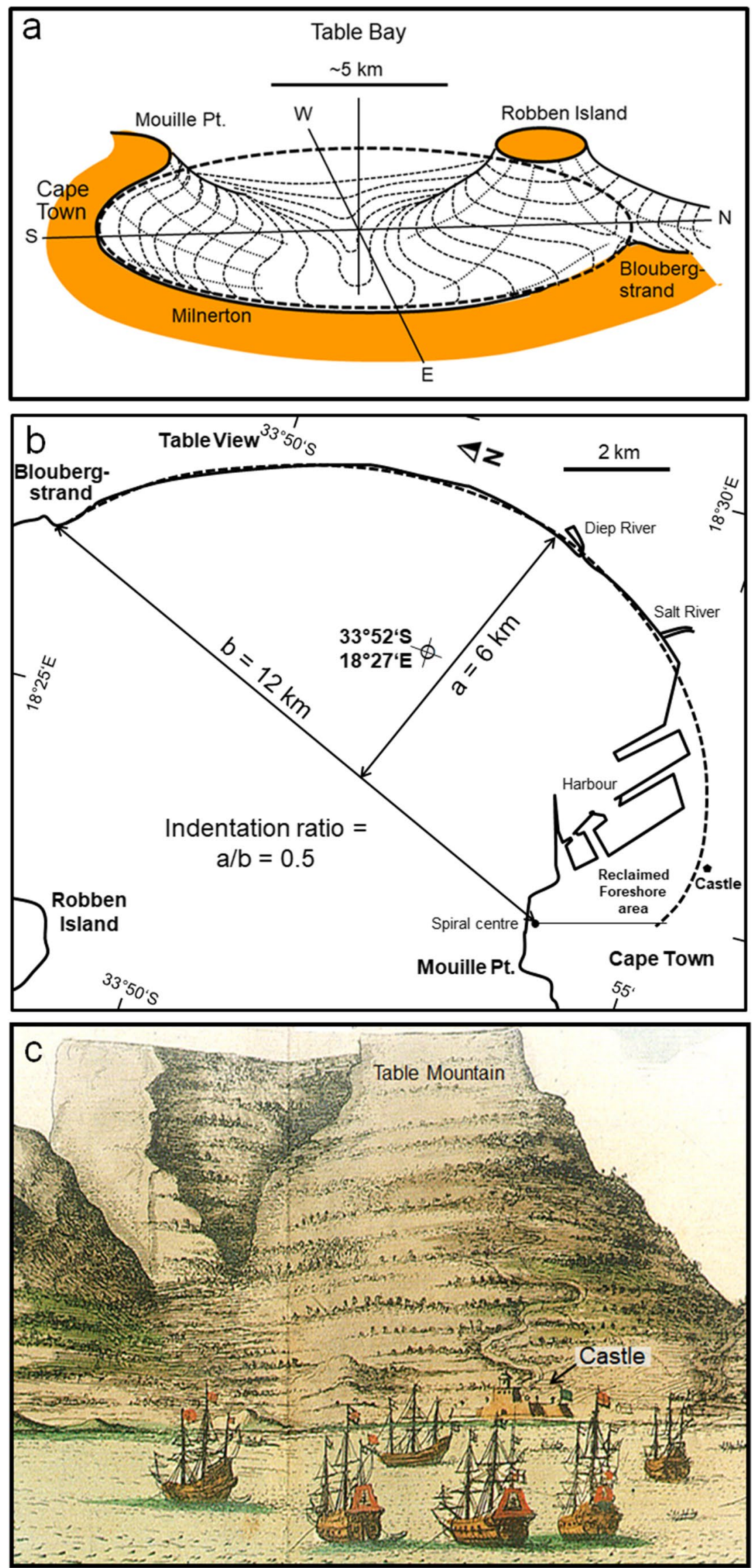

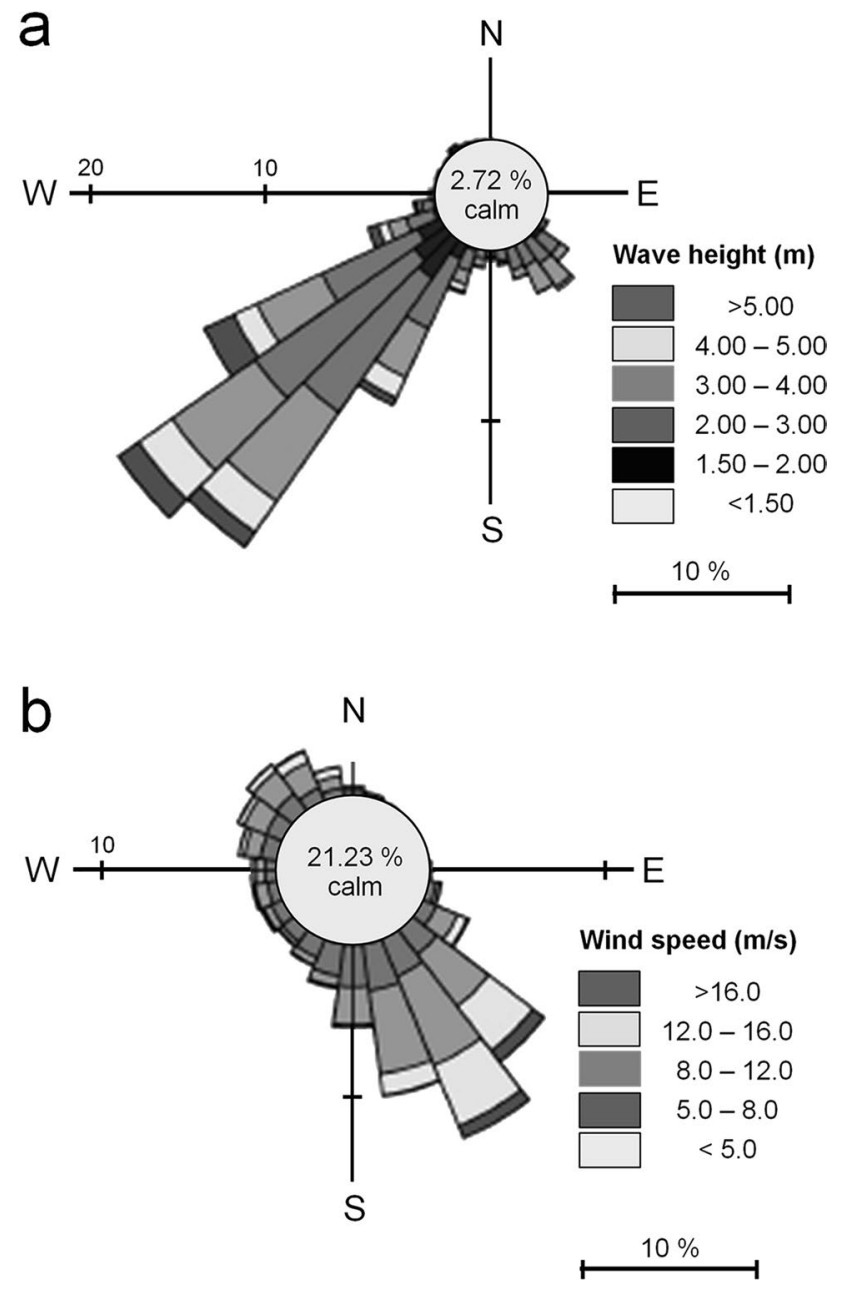

Fig. 4 a Directional frequency plot of significant wave heights. Note that this corresponds to the direction of the dominant waves. b Directional frequency plot of annual wind speed. Note the predominance of south-easterly winds (both data sets after Seifart 2012)

Southeast Trade Winds which can reach gale force strength (28-40 knots; $51.8-74.1 \mathrm{~km} / \mathrm{h} ; 14.4-20.5 \mathrm{~m} / \mathrm{s}$ ) for days on end, especially in spring and summer (October-April) when they are associated with intense upwelling of nutrient-rich waters along the west coast (e.g. Jury and Brundrit 1992).

\section{Sedimentological aspects}

Sand is supplied to Table Bay by the Diep and Salt rivers (cf. Figure $1 \mathrm{~b}$ ). As the catchments of both rivers are relatively small and their drainage areas composed of hard bedrock (granites, metamorphically modified shales and quartzites), the annual sand supply during the rainy season (southern winter period) is correspondingly low, but nevertheless sufficient to maintain a closed upper shoreface sand prism. This is also reflected in the patchy sediment cover of the bay below 12-15 m water depth. Due to the low sediment input,
Table Bay can be considered a sediment-starved embayment. For the same reason, Cape Town Harbour did not require regular maintenance dredging in the past. More recently, however, a planned dredging campaign was investigated for the purpose of achieving greater navigation depths for the accommodation of increasingly larger container vessels (Van Ballegooyen et al. 2006). This included assessment of the environmental viability of various dredge spoil disposal sites, the recommended sites being located in waters deeper than $40 \mathrm{~m}$ to the west of Table Bay. The sedimentological data presented in the present study therefore predate the anticipated dredging operations outlined above.

\section{Materials and methods}

To test the hypothesis of Wilson (1976), the shape of the bay was investigated in terms of a logarithmic spiral fitted to the shoreline. A good fit was achieved with a spiral centre located a short distance to the east of Mouille Point (Fig. 3b). At first sight, the inner part of the spiral appears contradictory because it is located onshore. However, the harbour and the so-called foreshore were constructed on land reclaimed from the sea. As evident from Fig. 3c, which is a section of a larger drawing of Table Bay as conceived by the British Hydrographer John Seller in 1693 (source: Cape Archives), the shoreline in former times passed close to Cape Town Castle. This can actually be taken as validation for the correct positioning of the log-spiral.

The spiral fit was accomplished manually by using a predefined log-spiral having a curvature corresponding to the indentation ratio of Table Bay $(\sim 0.5)$. As illustrated in Fig. $3 b$, the indentation ratio $(a / b)$ is the ratio between the maximum length of line a (in this case $\sim 6 \mathrm{~km}$ ) extending at right angles to the shoreline from line $\mathrm{b}$ connecting the spiral centre to the shoreline at its up-coast limit (here Blouberg Strand), and which has a length of $\sim 12 \mathrm{~km}$. Further details and the significance of this are provided in the results.

To obtain information on the physiography of Table Bay, a side-scan sonar survey was conducted in the summer of 1980/81 using a 100-kHz Klein Hydroscan 250 system. Navigational control was accomplished by means of a Plessey MRD 1 range positioning system with an accuracy of better than $1 \mathrm{~m}$. The strength of recorded backscatter signals of side-scan sonars typically allow the distinction between bedrock, gravel, coarser-grained sand, finer-grained sand and mud (cf. Flemming 1976a). Particular features such as faults, joints and bedding structures in rock outcrops or ripple marks in gravel and coarse sand are also highlighted. Concomitantly, a high-resolution boomer survey was conducted over the sediment-covered shoreface.

The distribution of sedimentary facies and textural parameters is based on overall 45 sediment samples (Fig. 2). The 
samples were partly collected by divers and partly by a small van Veen grab sampler in the summer of 1981/82 (Woodborne 1983). Overall 62 sampling stations were occupied, 17 of which failed to recover any sediment even after several attempts, suggesting that the seabed at these locations consisted of solid bedrock. Sample positions (cf. Fig. S1 of Electronic Supplementary Material, ESM) were determined by the same range positioning system used for the side-scan and boomer surveys. The samples were washed through a $63-\mu \mathrm{m}$ sieve to remove salt and traces of mud and then dried overnight. Where applicable, gravel fractions were removed by dry sieving. The remaining sand fractions were split down to masses suitable for settling tube analysis, generally 1-2 g (Flemming and Thum 1978). Settling velocities were converted to equivalent settling diameters by application of a computer algorithm developed for this purpose, being based on the experimental results of Gibbs et al. (1971).

It should be noted that gravel contents relate to the total sediment, whereas those of the sand fractions relate to the total sand fraction without gravel (cf. ESM Table S1). Sediment distribution patterns were generated by manual contouring. Identification of hydraulic populations and progressive mixing between neighbouring populations are based on the pattern originally recognised by Folk and Ward (1957) and later applied by, for example, Folk and Robles (1964) and Flemming (1988, 2015).

\section{Results}

\section{Planimetric shoreline shape}

The initial logarithmic spiral fitted to the shoreline has its centre (A) located just east of Mouille Point (Fig. 5). The shoreline of the bay is here defined as the transition between the beach (light colour on the satellite image) and the onset of the vegetation line (dark colour on the satellite image). To also account for the elliptical shape of the basin resulting from the juxtaposition of Robben Island opposite the headland of Table Bay, a second spiral was fitted from the opposite side by mirror-imaging the first spiral. After positioning spiral B such that it matched the shoreline south of Blouberg Strand, the two spiral centres (A, B) were connected to define a baseline. For reference purposes, the baseline was divided into equal parts by a line drawn perpendicular through the centre (apex line). The point where this line meets the shore represents the apex of the two converging spirals (Fig. 5a). The north axis of the chart was then rotated from the vertical by $\sim 73^{\circ}$ towards the west (left) to be aligned parallel to the baseline $(A-B)$. This was done for a better assessment of the spatial patterns of various parameters in relation to the morphometric symmetry of Table Bay. In the inset of Fig. 5a, log-scaled distances from spiral centre A to the shoreline (ordinate) are plotted against angles from the spiral centre at $5^{\circ}$ intervals (abscissa). The semi-logarithmic straightline relationship between the two parameters documents the near-perfect fit of the log-spiral to the shoreline. It can be mathematically expressed by the relationship:

$\ln y=1.1807+0.0107 x$

where $y$ is the distance from the spiral centre to the shoreline in $\mathrm{km}$, and $x$ is the angle in degrees. The correlation coefficient is $>0.99$. The same applies to the mirror-imaged spiral, which not only fits the shoreline south of Blouberg Strand but also traces the submarine ridge between Robben Island and Blouberg Strand. Together, the two converging log-spirals outline the ellipsoidal basin defined by the bathymetry (Fig. 2).

Schematically superimposed on the satellite image of Fig. 5b is an idealised refraction pattern of ocean swells entering the bay. The solid blue lines represent wave orthogonals, the broken blue lines wave crests. Wave refraction is caused by friction along the seabed under shoaling conditions, the pattern depending on the seabed configuration defined by the bathymetry. The distance between two adjacent orthogonals along a crest line corresponds to a particular wave energy increment. Starting at equal distances (and equal energy increments) at the entrance of the bay, the orthogonals of waves approaching at an angle corresponding to the orientation of the apex line begin to spread towards either side, the distances increasing with increasing refraction caused by the decreasing water depth in the basin. Each energy increment is correspondingly spread over increasingly larger distances, i.e. the wave energy per unit distance along a crest line decreases with increasing refraction.

Furthermore, due to the progressive decrease in water depth (shoaling), the refraction process is accompanied by progressively decreasing wave heights and, as a consequence, also decreasing wave energy per metre crest line. In the illustrated case, the highest energy occurs where the apex line meets the shore, and decreases in either direction alongshore. In reality wave refraction is not quite as symmetrical as shown in Fig. 5b, the reason being that the basin itself is not completely symmetrical, and that the bathymetry is locally distorted by high rock pinnacles, especially on the Robben Island side of the bay entrance (cf. Figure 2). A more realistic refraction pattern produced by $12 \mathrm{~s}$ waves approaching from the SW can be viewed in MacHutchon et al. (2020). It should be noted that the refraction pattern varies with varying angles of wave approach.

Another feature characterising Table Bay is the frequent occurrence of a distinct suspension cloud above the rocky ridge linking Robben Island and Blouberg Strand. The intensity of the cloud varies in response to the oceanographic forcing conditions existing at any particular time. In Fig. 5b, it can be faintly seen on the northern side of the log-spiral. It 
Fig. 5 a Log-spiral fits to the shoreline of Table Bay. The spiral centred on point $B$ is a mirror-image of the spiral centred on point A. Note the proximity of Cape Town Castle to the shoreline predicted by $\log$-spiral A, which is in agreement with the sketch of 1693 shown in Fig. 3c. Inset diagram: Distance to the shoreline from spiral centre A versus angle from the spiral centre at $5^{\circ}$ intervals. Note the near-perfect fit. b Satellite picture of Table Bay showing the near-perfect fit of the shoreline by the two converging logarithmic spirals centred around points $\mathrm{A}$ and $\mathrm{B}$ Also shown are the diverging orthogonals and curved crest lines of long-period ocean swells that would result from refraction in the case of an idealised elliptical basin as visualised by Wilson (1976)
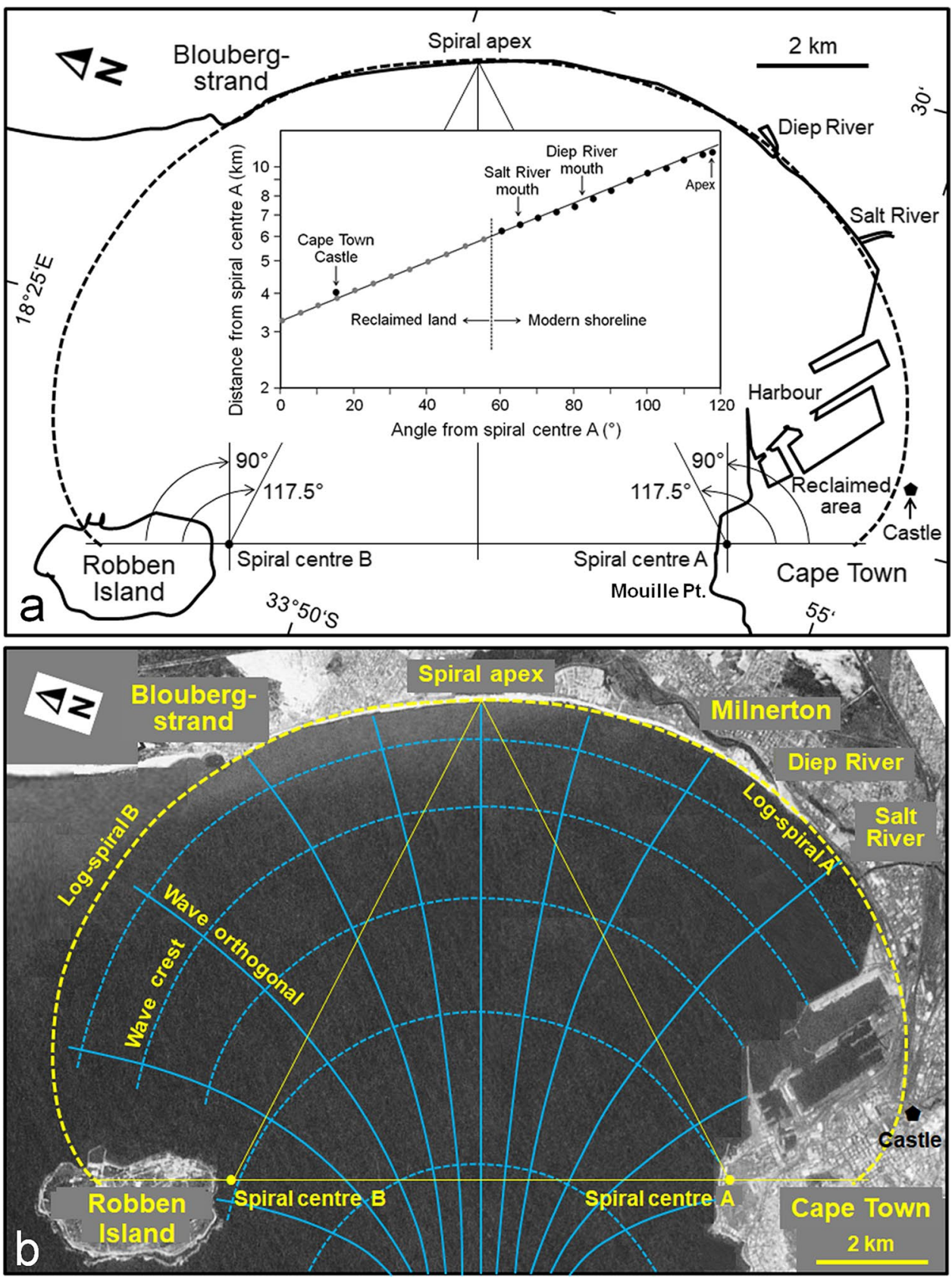

emulates a tombolo that would exist if the ridge were higher and sufficient sediment available to close the gap.

\section{Physiography of the Table Bay basin}

On the basis of the side-scan survey, three prominent physiographic facies were distinguished: bedrock (grey), coarsergrained sand and gravel (orange) and finer-grained sand (yellow) (Fig. 6a). The sonograph in Fig. 6b gives an impression of the acoustic differentiation between bedrock (darker shading) and the sediment infilling a channel incised into the bedrock (lighter shading). Also prominent are the fold structures in the Malmesbury shale forming the bedrock abrasion platform. The infilled channel is located near the centre of the bay where the palaeo-valleys of the Diep and Salt rivers have merged into a single channel (Fig. 6a). Figure 6c, in turn, shows the courses of the Diep and Salt rivers as revealed by the depth-to-bedrock contours after the sediment cover has been stripped on the basis of the boomer data.

Of particular interest in Fig. $6 \mathrm{a}$ is the similarity in the trend of the distribution patterns of the coarser- and finer-grained sediment facies to either side of the apex line. Thus, besides lining the entire upper shoreface from the shore to a depth of $12-15 \mathrm{~m}$, the finer-grained sediment also occurs in a narrow 

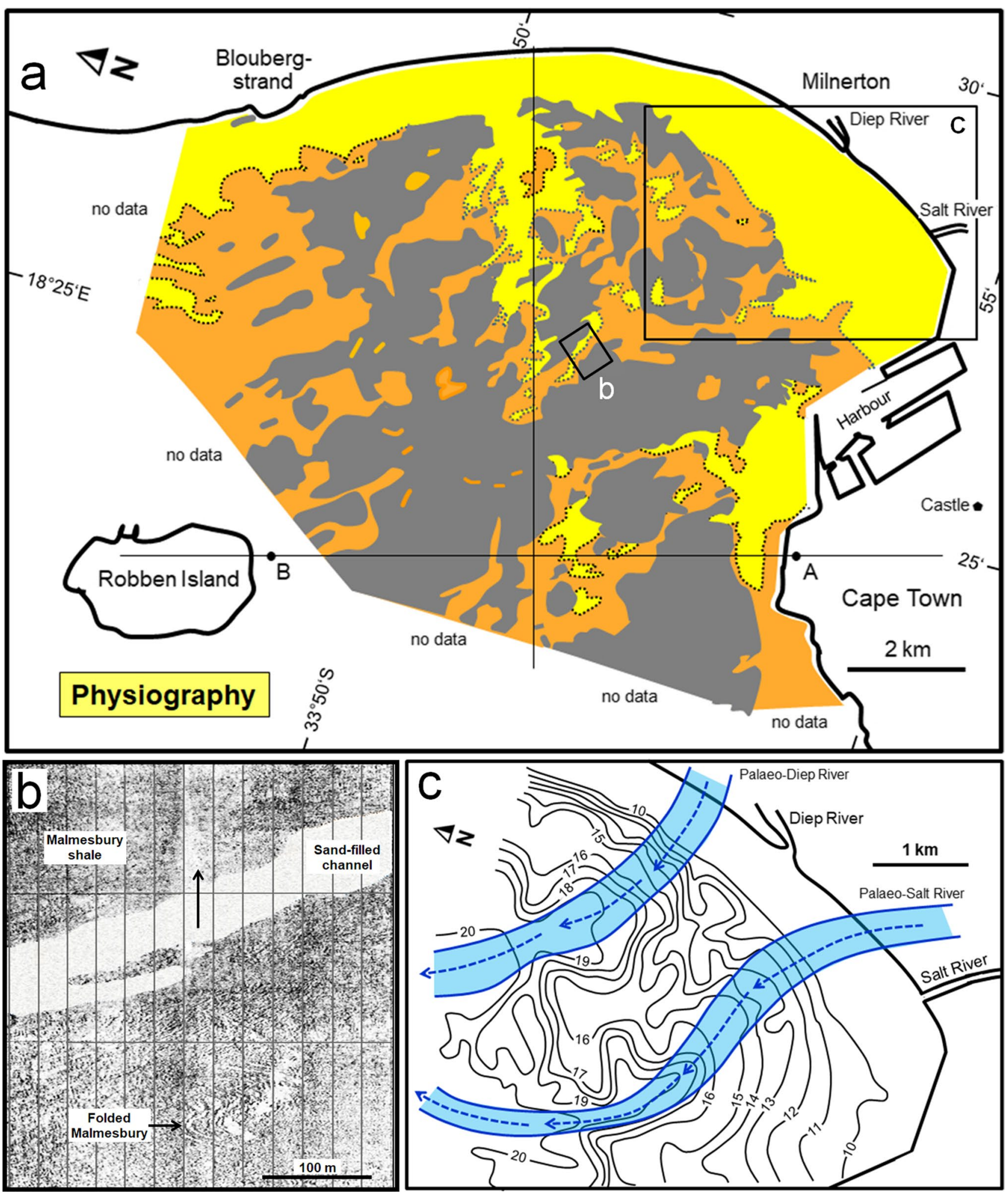

Fig. 6 a Physiographic chart showing the distribution of bedrock (dark grey) as well as areas dominated by coarse-medium sand (orange) and fine-very fine sand (yellow). b Side-scan sonar image illustrating a sand-filled channel cut into bedrock (Malmesbury shale) (small inset box in a). c Blow-up of the southeastern bay sector (large inset box in a) displaying the bathymetry at $1 \mathrm{~m}$ depth intervals starting at $10 \mathrm{~m}$, and the inferred location of the Diep and Salt river palaeo-valleys 
and patchy strip across the centre of the bay, being more or less aligned with the apex line. This suggests a quasi-mirrorimaged sediment distribution with the apex line as mirror. The pattern is characterised by increasingly coarser sediment with distance from the apex line. It should be noted that the extensive rock platform identified by the side-scan survey locally displays superimposed thin patches of sediment not resolved by the acoustic backscatter but observed by divers during sampling.

\section{Sediment distribution patterns}

The striking similarity in the distribution of the two major sedimentary facies to either side of the apex line identified on the physiographic map (Fig. 6a) is reinforced to various degrees by the patterns of all other sedimentary parameters (Fig. 7). The least effect is seen in the distribution of gravel (Fig. 7a), but it is clearly evident in the distribution of coarse/very coarse sand (Fig. 7b), and particularly in the distribution patterns of medium (Fig. 7c), fine (Fig. 7d) and very fine sand (Fig. 7e). Notable here are the opposing trends of the coarse/very coarse and medium sand fractions, on one hand, and those of the fine and very fine sands, on the other. This is also reflected in the distribution of mean diameters (Fig. 7f). It confirms the existence of two dominant sediment populations, a coarser-grained one and a finer-grained one, as already suggested by the acoustic facies map (Fig. 6a).

The spatial partitioning is also evident in the distribution of bioclastic material $\left(\mathrm{CaCO}_{3} ; \mathrm{Fig}\right.$. $\left.8 \mathrm{a}\right)$ produced by the breakdown of shell-bearing marine organisms. It correlates particularly well with the coarse/very coarse and medium sand fractions. This is not surprising as the $\mathrm{CaCO}_{3}$-content increases with increasing grain size, to the point of reaching almost $100 \%$ in the very coarse sand fraction (Fig. 8b). The pattern is also reflected in the distribution of textural facies (Fig. 8c) and the sedimentary lithology (Fig. 8d).

The existence of essentially two hydraulic populations, i.e. a coarse-grained one and a fine-grained one, is confirmed by the mixing progression defined in the pooled data illustrated in Fig. 9. The inverted v-shaped relationship between mean grain size and sorting is typical for the mixing between two sediment populations. Whilst the parent populations are well sorted, the sorting progressively decreases in proportion to the content of coarse/fine sediment in the course of mixing. Poorest sorting occurs where the two populations are mixed in equal proportions. In Table Bay, such mixing progressions exist to either side of the apex line.

\section{Discussion}

The results of this study demonstrate that an intimate relationship exists between the ellipsoidal shape of Table Bay, its physiography and the distribution of sediments. Thus, the nearshore sand prism extends offshore down to water depths of $12-15 \mathrm{~m}$, thereby defining the local shoreface. Its seaward limit is in good agreement with the so-called closure depth of Hallermeier (1978, 1981; cf. also Hamon-Kerivel et al. 2020). According to this approach, the closure depth for a wave period of $T=12 \mathrm{~s}$ and a significant storm wave height of $H=5 \mathrm{~m}$ is located at a water depth of $10.2 \mathrm{~m}$ (for more information, in particular also the closure-depth equation, the reader is referred to ESM Table S2).

With respect to the hypothesis of Wilson (1976) that the ellipsoidal shape of the Table Bay basin is prone to resonant oscillations, the data presented in this study can be viewed as strong supportive evidence. Wilson conceived barometric pressure differences as the main trigger mechanism (cf. also Hibiya and Kajiura 1982, in this context), although forcing by internal solitary waves (Giese et al. 1982) or reinforcement by strong and sustained winds blowing in alignment with the long axis of elongate water bodies are also known to produce long-period standing waves (e.g. Wübber and Krauss 1979; Metzner et al. 2000).

In the case of Table Bay, a well-known phenomenon is the strong, seasonally blowing Southeast Trade Wind (Southeaster) which frequently reaches gale force strength for days on end in the southern spring and summer months (October-March). The strong wind pushes water northwards away from Cape Town harbour towards the gap between Robben Island and Blouberg Strand. What influence this may have on the hydrography of Table Bay, other than generating a northward directed alongshore current and intense upwelling along the west coast, is unknown. Wilson (1954) discounted the Southeaster as having any influence on oscillatory motions in the bay, and instead favoured barometric pressure oscillations as the trigger mechanism for seiching. This would be in line with the so-called coastal-trapped waves observed by, for example, Schumann (1983) and Shillington (1984) who associated them with barometric pressure variations caused by low-pressure systems passing the subcontinent during the winter months. Approaching the coast from the west, the lowpresssure systems are diverted southwards around the Cape Peninsula to continue along the south and east coasts of South Africa (Schumann 1983). Whilst moving southwards, the successive pressure-induced coastal waves are intercepted in Table Bay where they are reflected to produce standing waves or seiches (Shillington 1984). According to Merian (1828; cf. also Proudman 1953), the maximum period of a surface seiche in elongate basins can be estimated by the relationship:

$T=\frac{1}{n} \cdot \frac{2 L}{\sqrt{g h}}$

where $T$ is the longest natural period (s), $L$ is the length of the basin (m), $h$ the average depth of the water body (m) and $g$ the acceleration due to gravity $\left(\mathrm{m} / \mathrm{s}^{2}\right)$. 

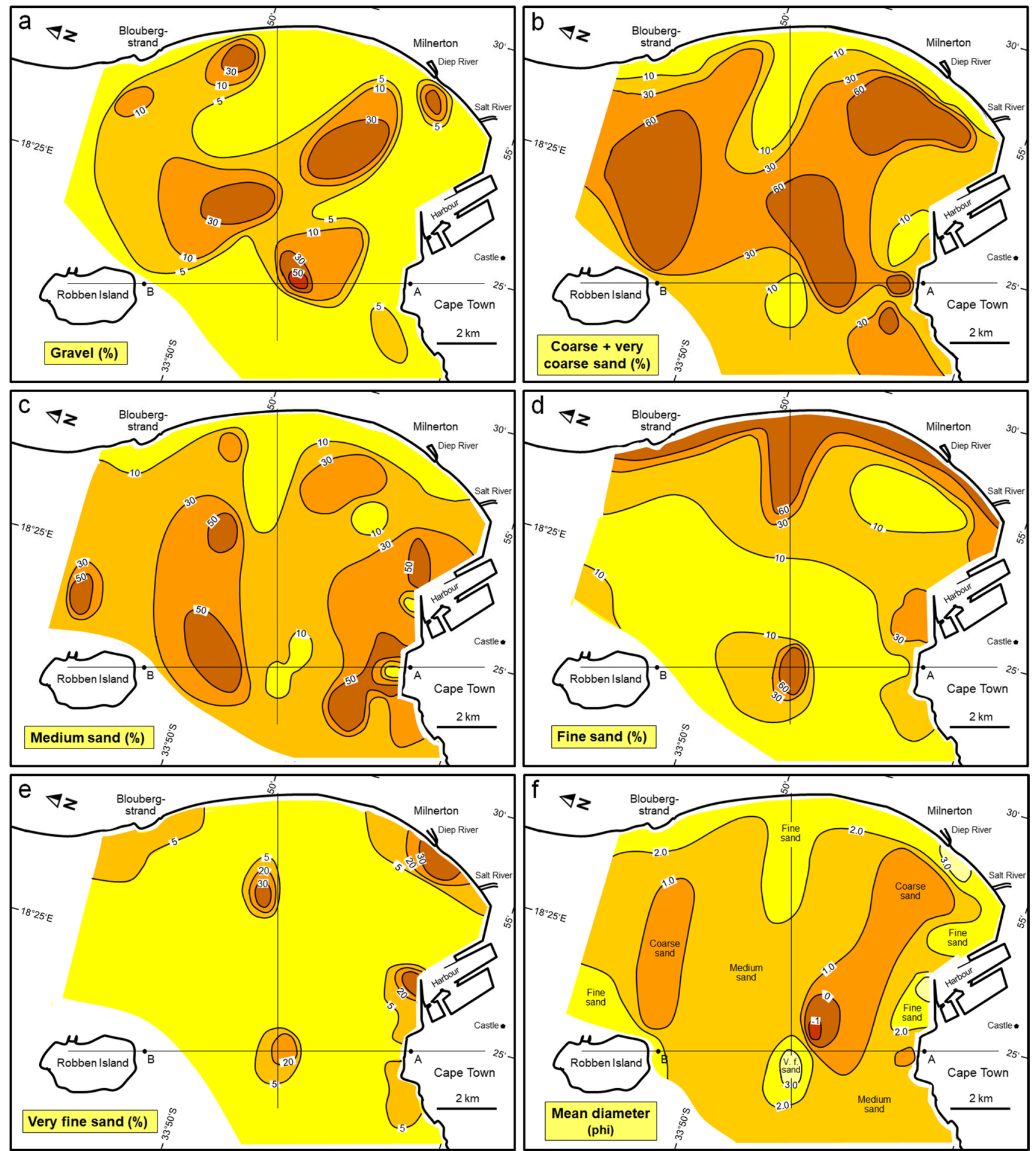

Fig. 7 Distribution of individual grain size fractions and the mean diameter in Table Bay. a Gravel (\%); b coarse +very coarse sand (\%); c medium sand (\%); $\mathbf{d}$ fine sand (\%); e very fine sand (\%); f mean diameter (phi)

The distribution patterns of textural sediment parameters in Table Bay strongly argue in favour for the dominating occurrence of a seiche characterised by a single node and two antinodes. A simplified two-dimensional model of such a seiche, together with the associated circulation cells, is illustrated in Fig. 10 (modified after Allen 1985). It quite adequately explains the observed sediment distribution patterns. With a length of $\sim 12,000 \mathrm{~m}$ and an average depth 

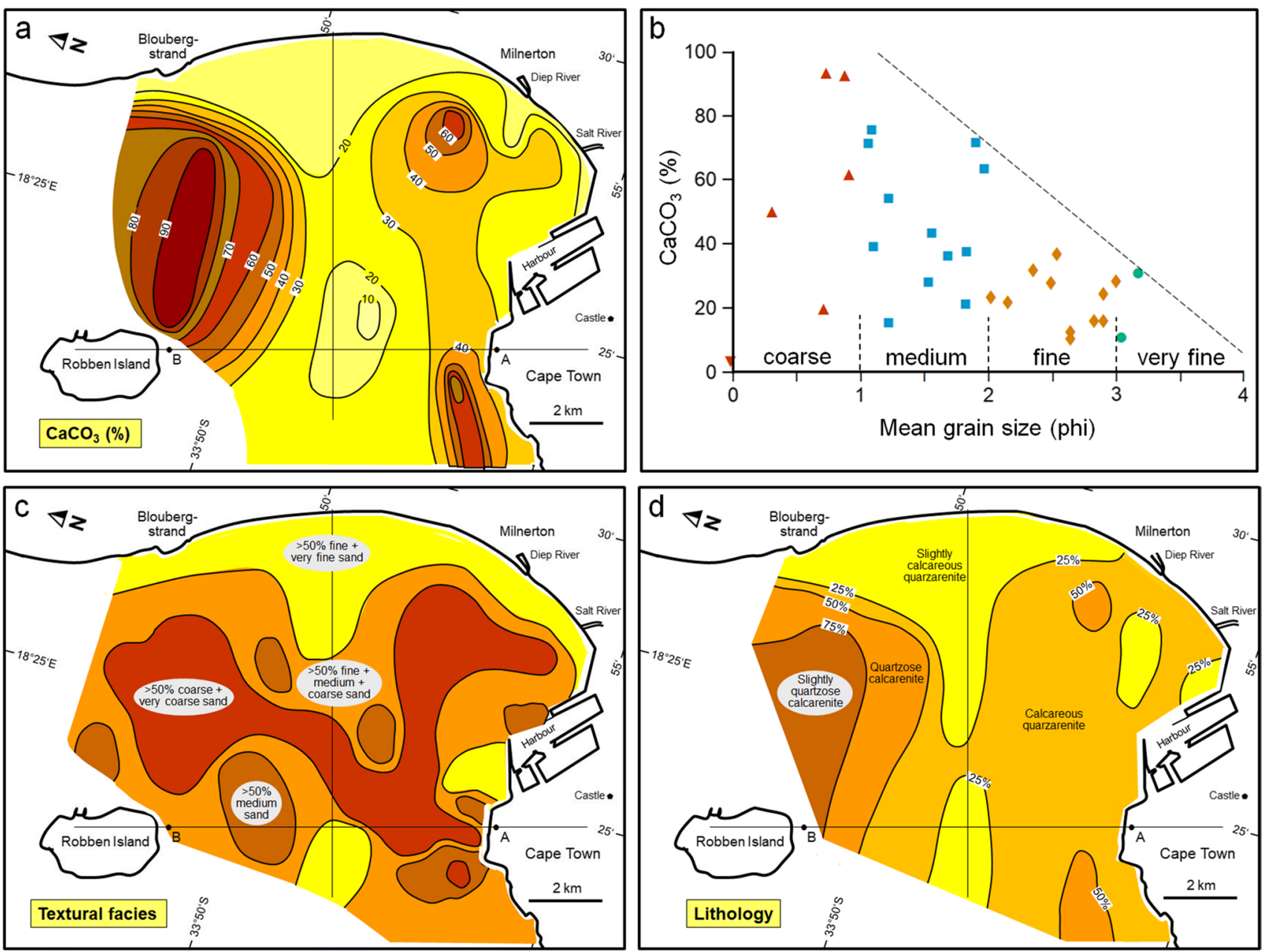

Fig. 8 a Distribution of calcium carbonate $\left(\mathrm{CaCO}_{3}\right)$ in Table Bay. b Calcium carbonate content $(\%)$ versus mean diameter (phi). Note the rapid decrease in maximum carbonate content with decreasing grain

size (coloured symbols represent specific grain-size fractions). c Distribution of textural sedimentary facies in Table Bay. d Lithology of the modern sediments in Table Bay

of $\sim 12 \mathrm{~m}$, the longest oscillation period of a seiche in Table Bay characterised by a single node $(n=1)$ would be $\sim 37 \mathrm{~min}$. Although more complex situations could also be conceived, the only alternative would be a seiche characterised by three nodes because one of the nodes must inherently be located in the centre of the bay along the apex line. However, there is no evidence for an influence of such higher mode oscillations in the sediment distribution patterns. Applying the one-node model to the bay proper, the observed textural trends can be interpreted to represent two opposing mixing progressions located on either side of the apex line (Fig. 9).

Thus, if one assumes that the initially subaerially exposed basin was draped by poorly sorted sediment composed of grain sizes spanning the range from very fine sand (3.2 phi; $0.1 \mathrm{~mm})$ to very coarse sand $(-0.1$ phi; $1.07 \mathrm{~mm})$ then, with the onset of seiching after the basin was invaded by the sea in the course of the postglacial sea-level rise, the sediment was reworked and, in the course, progressively size-sorted. In the process, wave action at the seabed caused the finer grain sizes to be suspended, whereas the gravel and coarser particles remained more or less in place. The suspended fine sand was then gradually (step-wise) transported in the direction of the flow in the boundary layer, i.e. towards the apex line, where it became concentrated. As this process is inherently inefficient, some fine sand lags behind or remains trapped between coarser particles, thereby defining the observed mixing pattern, which can also be understood to represent an unmixing process.

The mechanism proposed above is not unrealistic when considering the local wave climate. Applying linear (Airy) wave theory (e.g. Dean and Dalrymple 2002; Masselink and Hughes 2003), maximum near-bed oscillatory currents $\left(U_{\max }\right)$ were calculated for significant wave periods $\left(T_{\mathrm{s}}\right)$ of 8,10 and $12 \mathrm{~s}$, and significant wave heights $\left(H_{\mathrm{s}}\right)$ of 3 and $4 \mathrm{~m}$ (cf. Table 1), in all cases valid for a water depth of $20 \mathrm{~m}$, which represents the average basal depth in the centre 


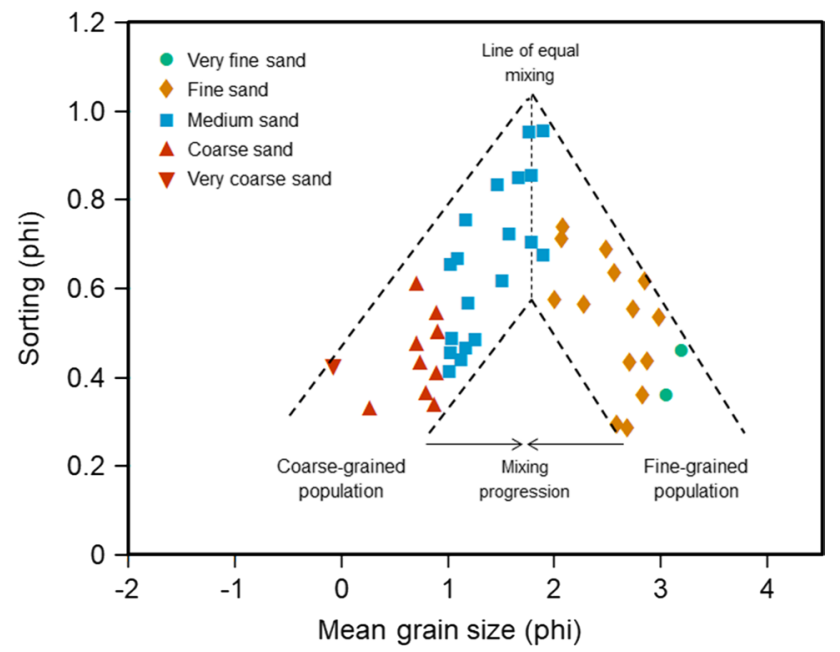

Fig. 9 Diagram illustrating the relationship between sediment sorting (phi) and mean grain size (phi). The inverted v-shaped pattern reveals the progressive mixing between a coarse-grained and a fine-grained sediment population (cf. Figure 6a) (coloured symbols as in Fig. 8b)

of the ellipsoidal Table Bay basin (cf. Figure 2). These are contrasted with the critical erosion velocities $\left(U_{\text {crit }}\right)$ for the average grain sizes of the coarse $(D=0.5 \mathrm{~mm})$ and fine $(D=0.125 \mathrm{~mm})$ endmember sand populations (calculations based on the empirical equation of Flemming 2005; cf. ESM Table S3), on one hand, and the critical velocities for the transition to upper plane bed conditions $\left(U_{\mathrm{upb}}\right)$, on the other. For $D_{\text {mean }}=0.5 \mathrm{~mm}, U_{\text {upb }}=1.4 \mathrm{~m} / \mathrm{s}$ and for
$D_{\text {mean }}=0.125 \mathrm{~mm}, U_{\text {upb }}=0.7 \mathrm{~m} / \mathrm{s}$. As these velocities are independent of the wave period (cf. Clifton 1976), they apply in all cases. Details about the procedure and the equations involved can be found in ESM Table S3.

When assessing the various parameters for the analysed wave periods and heights relative to each other (Table 1), two aspects are of particular importance in the context of this study:

a) At $20 \mathrm{~m}$ water depth, the deep-water wavelengths have shortened by $11 \%$ for the $8 \mathrm{~s}$ waves, $22 \%$ for the $10 \mathrm{~s}$ waves and $32 \%$ for the $12 \mathrm{~s}$ waves due to friction along the seabed, whilst the distance along the crests between adjacent orthogonals has more than doubled due to refraction (cf. Figure 5b). Within the bay, wave energy has thus decreased considerably relative to that at the same depth for the deep-water waves.

b) The $U_{\max }$ velocities are all below the upper plane bed velocities for the coarse $(0.5 \mathrm{~mm})$ endmember population but, with the exception of the $T_{\mathrm{s}}=8 \mathrm{~s}$ and $H_{\mathrm{s}}=3 \mathrm{~m}$ case, they exceed the upper plane bed velocities for the fine $(0.125 \mathrm{~mm})$ endmember population. In effect, this means that, under storm-wave conditions, the coarse endmember sands are preferentially moved in bedload to form large ripples (e.g. Flemming 1976b), whereas the fine endmember sands are predominantly lifted into suspension. Because the flows caused by seiching are, more or less, at right angles to the wave-induced flows, the suspended fine sands will be stepwise displaced
Fig. 10 Schematic diagram illustrating the partitioning and direction of fluid flow induced by a standing wave (seiche) in a large marine basin (modified after Allen 1978). Note the converging flows in the boundary layer towards the nodal point

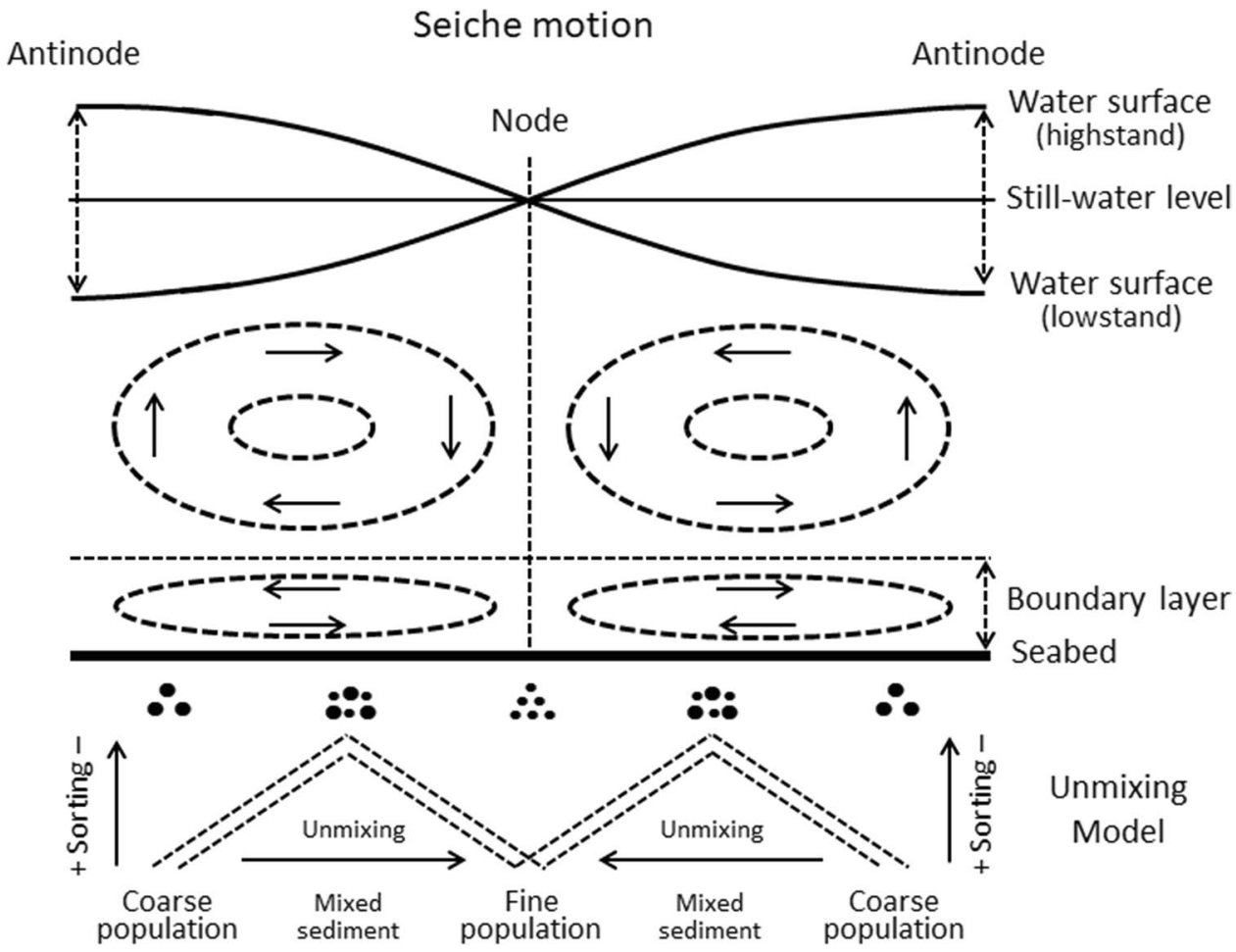


Table 1 Maximum near-bed oscillatory current velocities $\left(U_{\max }\right)$ of typical storm waves at a water depth of $20 \mathrm{~m}$ in Table Bay for significant wave periods $\left(T_{\mathrm{s}}\right)$ in the range of $8-12 \mathrm{~s}$ and significant wave heights $\left(H_{\mathrm{s}}\right)$ of 3-4 m, together with the critical erosion velocities
$\left(U_{\text {crit }}\right)$ for mean grain sizes of $D=0.5 \mathrm{~mm}$ (coarse endmember population) and $D=0.125 \mathrm{~mm}$ (fine endmember population); $L_{0}$ and $L_{20}$ denote the deep-water wavelength and the wavelength in $20 \mathrm{~m}$ water depth, respectively

\begin{tabular}{lllllll}
\hline $\begin{array}{l}T_{\mathrm{s}} \\
(\mathrm{s})\end{array}$ & $\begin{array}{l}L_{0} \\
(\mathrm{~m})\end{array}$ & $\begin{array}{l}L_{20} \\
(\mathrm{~m})\end{array}$ & $\begin{array}{l}H_{\mathrm{s}} \\
(\mathrm{m})\end{array}$ & $\begin{array}{l}U_{\max } \\
(\mathrm{m} / \mathrm{s})\end{array}$ & $\begin{array}{l}U_{\text {crit }}(\mathrm{m} / \mathrm{s}) \\
\text { for } D=0.5 \mathrm{~mm}\end{array}$ & $\begin{array}{l}U_{\text {crit }}(\mathrm{m} / \mathrm{s}) \\
\text { for } \\
D=0.125 \mathrm{~mm}\end{array}$ \\
\hline 8 & 99.84 & 88.7 & 3 & 0.61 & 0.25 & 0.14 \\
8 & 99.84 & 88.7 & 4 & 0.81 & 0.25 & 0.14 \\
10 & 156.0 & 121.0 & 3 & 0.76 & 0.28 & 0.16 \\
10 & 156.0 & 121.0 & 4 & 1.02 & 0.28 & 0.16 \\
12 & 224.64 & 152.0 & 3 & 0.85 & 0.29 & 0.17 \\
12 & 224.64 & 152.0 & 4 & 1.13 & 0.29 & 0.17 \\
\hline
\end{tabular}

towards the node, i.e. in the direction of the apex line, as schematically illustrated in Fig. 10 and recorded in the distribution patterns of the textural parameters.

The observed distribution patterns are also compatible with recent modelling studies investigating the nature of large-scale oscillatory motions in elliptical bays (e.g. Pritchard and Hogg 2003; Park et al. 2016), the latter study having identified tidally forced shelf resonances as a primary driver of continuous seiching. In view of the different trigger mechanisms identified in various studies (cf. Wübber and Krauss 1979; Hibiya and Kajiura 1982; Giese et al. 1982; Metzner et al. 2000), the mechanism responsible for the seiching in Table Bay outlined above remains unverified, although the coastal trapped wave model provides the most plausible solution.

\section{Conclusions and recommendations}

On the basis of the results of this study, the following conclusions are drawn:

a) Due to the presence of Robben Island opposite the headland of Table Bay, the bathymetry describes an ellipsoidal basin, the shoreline of which can be outlined by two converging logarithmic spirals.

b) The similarity of sediment distribution to either side of the apex line suggests the mixing/unmixing of two hydraulic populations, which strongly supports the occurrence of oscillatory motions (seiches) in the bay.

c) It is recommended that the seiching phenomenon be further investigated in order to verify its existence and, in the event, establish the trigger mechanism and its precise nature.
Supplementary Information The online version contains supplementary material available at https://doi.org/10.1007/s00367-021-00718-3.

Funding Open Access funding enabled and organized by Projekt DEAL.

\section{Declarations}

Conflict of interest The authors declare no competing interests.

Open Access This article is licensed under a Creative Commons Attribution 4.0 International License, which permits use, sharing, adaptation, distribution and reproduction in any medium or format, as long as you give appropriate credit to the original author(s) and the source, provide a link to the Creative Commons licence, and indicate if changes were made. The images or other third party material in this article are included in the article's Creative Commons licence, unless indicated otherwise in a credit line to the material. If material is not included in the article's Creative Commons licence and your intended use is not permitted by statutory regulation or exceeds the permitted use, you will need to obtain permission directly from the copyright holder. To view a copy of this licence, visit http://creativecommons.org/licenses/by/4.0/.

\section{References}

Allen JRL (1985) Principles of physical sedimentology. George Allen and Unwin, London

Bremner JM (1983) Properties of logarithmic spiral beaches with particular reference to Algoa Bay. In: McLachlan A, Erasmus T (eds) Sandy Beaches as Ecosystems. Dr W Junk Publ, The Hague, pp 97-113

Bremner JM (1991) Logarithmic spiral beaches with emphasis on Algoa Bay. Geol Surv S Afr Bull 100:147-164

Bremner JM, Le Blond PH (1974) On the planimetric shape of Wreck Bay, Vancouver Island. J Sediment Res 44:1155-1165

Clifton HE (1976) Wave-formed sedimentary structures - a conceptual model. In: Davis RA Jr, Ethington RL (eds) Beach and nearshore sedimentation. SEPM Spec Publ 24:126-148

Darbyshire M (1963) Long waves on the coast of the Cape peninsula. Deutsche Hydrogr Zeitschr (today Ocean Dynamics) 16:167-185

Darbyshire J, Darbyshire M (1964) Wave observations in South African waters. S Afr J Sci 60:183-189 
Darbyshire M, Pritchard E (1966) Sea waves near the coasts of South Africa. Deutsche Hydrogr Zeitschr (today Ocean Dynamics) 19:218-225

Dean RG, Dalrymple RA (2002) Coastal processes with engineering applications. Cambridge University Press, Cambridge

De Wet WM (2012) Bathymetry of the South African continental shelf. MSc thesis, Department of Geological Sciences, University of Cape Town, South Africa

Flemming BW (1976) Side-scan sonar: a practical guide. Int Hydrogr Rev 53:65-92

Flemming BW (1976) Rocky Bank - evidence for a relict wave-cut platform. Ann S Afr Mus 71:33-48

Flemming BW (1977) Distribution of recent sediments in Saldanha Bay and Langebaan Lagoon. Trans Roy Soc S Afr 42:317-340

Flemming BW (1988) Process and pattern of sediment mixing in a microtidal coastal lagoon along the west coast of South Africa. In: de Boer PL, van Gelder A, Nio SD (eds) Tide-influenced sedimentary environments and facies. D Reidel Publ Co, Dordrecht, pp 275-288

Flemming BW (2005) The concept of wave base: fact and fiction. In: Haas H, Ramseyer K, Schlunegger F (eds) Abstracts. Sediment 2005, 18 - 20 July 2005, Gwatt, Lake Thun, Switzerland. Schriftenreihe der Deutschen Gesellschaft für Geowissenschaft 38, p 57

Flemming BW (2015) Depositional processes in Saldanha Bay and Langebaan Lagoon (Western Cape, South Africa). CSIR Research Report 362 (revised edition; accessible on ResearchGate)

Flemming BW, Thum AB (1978) The settling tube - a hydraulic method for grain size analysis of sands. Kiel Meeresforsch Sonderh 4:82-95

Folk RL, Ward WC (1957) Brazos River bar: a study in the significance of grain size parameters. J Sediment Res 27:3-26

Folk RL, Robles R (1964) Carbonate sediments of Isla Perez, Alacran Reef Complex, Yucatan. J Geol 72:255-292

Franceschini G, Compton JS, Wigley RA (2003) Sand transport along the Western Cape coast: gone with the wind? S Afr J Sci 99:317-318

Gallop SL, Kennedy DM, Loureiro C, Naylor LA, Muñoz-Pérez JJ, Jackson DWT, Fellowes TE (2020) Geologically controlled sandy beaches: their geomorphology, morphodynamics and classification. Science of the Total Environment 731, 139123

Gibbs RJ, Matthews MD, Link DA (1971) The relationship between sphere size and settling velocity. J Sediment Res 41:7-18

Giese GS, Hollander RB, Fancher JE, Giese BS (1982) Evidence of coastal seiche excitation by tide-generated internal solitary waves. Geophys Res Lett 9:1305-1308

Göttisheim J, Flemming BW (2013) The coast between Cabo de Santa Maria (Portugal) and Rabat (Morocco): a mega-size headland-bay shoreline under control of the North Atlantic swell? Geo-Mar Lett 33:183-193. https://doi.org/10.1007/s00367-012-0308-9

Hallermeier RJ (1978) Uses for a calculated limit depth to beach erosion. Coast Eng 1:1493-1512

Hallermeier RJ (1981) A profile zonation for seasonal sand beaches from wave climate. Coast Eng 4:253-277

Hamon-Kerivel K, Cooper A, Jackson D, Sedrati M, Guisado-Pintado E (2020) Shoreface mesoscale morphodynamics: a review. EarthSci Rev 209, 103330

Harris TFW, Marshall J, Shillington FA (1972) Wind waves in Cape waters: features of their frequency spectra and associated generating conditions. In: CSIR (ed) ECOR Symposium on The Ocean's Challenge to S.A. Engineers, Cape Town, Proceedings S 71

Hibiya T, Kajiura K (1982) Origin of the Abiki phenomenon (a kind of Seiche) in Nagasaki Bay. J Oceanogr Soc Japan 38:172-182

Hsu JCR, Silvester R, Xia YM (1987) New characteristics of equilibrium shape bays. Proceedings of the 8th Australasian Conference on Coastal and Ocean Engineering, Launceston, Tasmania, pp 140-144
Hsu JCR, Evans C (1989) Parabolic bay shapes and applications. Proc Austral Inst Civil Eng 87:557-570

Jackson DWT, Cooper JAG (2010) Application of the equilibrium planform concept to natural beaches in Northern Ireland. Coast Eng 57:112-123

Joubert JR, van Niekerk JL (2013) South African wave energy resource data - a case study. Centre for Renewable and Sustainable Energy Studies (CRSES), Faculty of Engineering, University of Stellenbosch, South Africa

Jury MR, Brundrit GB (1992) Temporal organization of upwelling in the southern Benguela ecosystem by resonant coastal trapped waves in the ocean and atmosphere. S Afr J Mar Sci 12:219-224

Kimberley MM (1989) Fitting a logarithmic spiral to the shoreline of a headland-bay beach. Comput Geosci 15:1089-1108

Krumbein WC (1944) Shore processes and beach characteristics. US Army Beach Erosion Board, Tech Mem 3

Le Blond PH (1979) An explanation of the logarithmic spiral plan shape of headland bay beaches. J Sediment Res 49:1093-1100

MacHutchon MR, de Beer CH, van Zyl FW, Cawthra HC (2020) What the marine geology of Table Bay, South Africa, can inform about the western Saldania Belt, geological evolution and sedimentary dynamics of the region. J Afr Earth Sci 162, doi https://doi.org/ 10.1016/j.jafrearsci.2019.103699

Masselink G, Hughes MG (2003) Introduction to Coastal Processes \& Geomorphology. Hodder Arnold, London

Merian J R (1828) Über die Bewegung tropfbarer Flüssigkeiten in Gefässen. PhD thesis, University of Basel. Schweighauser, Basel

Metzner M, Gade M, Hennings I, Rabinovich AB (2000) The observation of seiches in the Baltic Sea using a multi-data set of water levels. J Mar Syst 24:67-84

Park J, MacMahan J, Sweet WV, Kotun K (2016) Continuous seiche in bays and harbors. EGU Ocean Sci 12:355-368

Phillips JD (1985) Headland-bay beaches revisited: an example from Sandy Hook, New Jersey. Mar Geol 65:21-31

Pritchard D, Hogg AJ (2003) Suspended sediment transport under seiches in circular and elliptical basins. Coast Eng 49:43-70

Proudman J (1953) Dynamical oceanography. Methuen, London

Rossouw J (1989) Design waves for the South African coastline. PhD thesis, University of Stellenbosch, South Africa

Rowe CD, Backeberg NR, van Rensburg T, Maclennan SA, Faber C, Curtis C, Viglietti PA (2010) Structural geology of Robben Island: implications for the tectonic environment of Saldanian deformation. S Afr J Geol 113:57-72

Schumann EH (1983) Long-period coastal trapped waves off the southeast coast of Southern Africa. Cont Shelf Res 2:97-107

Seifart C (2012) The long term impact of the Seli One shipwreck on the Table Bay beaches. MSc thesis, Faculty of Civil Engineering, Stellenbosch University, South Africa

Shillington FA (1982) Wave energy variation near Cape Town, South Africa. In: ASCE (ed) 18th ICCE, Cape Town, Proceedings, pp 473-484

Shillington FA (1984) Long period edge waves off Southern Africa. Cont Shelf Res 3:343-357

Shillington FA, Harris TFW (1978) Surface waves near Cape Town and their associated atmospheric pressure distribution over the South Atlantic. Deutsche Hydrogr Zeitschr (ocean Dynamics) 31:67-82

Short AD, Masselink G (1999) Embayed and structurally controlled beaches. In: Short AD (ed) Handbook of Beach and Shoreface Morphodynamics. John Wiley \& Sons, Chichester, pp 230-250

Terpstra PD, Chrzastowski MJ (1992) Geometric trends in the evolution of a small log-spiral embayment on the Illinois shore of Lake Michigan. J Coast Res 8:603-617

Van Ballegooyen RC, Diedericks G, Weitz N, Bergman S, Smith G (2006) Ben Schoeman Dock Berth Deepening Project: dredging and disposal of dredge spoil modelling specialist study. CSIR Report No CSIR/NRE/ECO/ER/2006/0228/C 
Wilson BW (1953) The mechanism of seiches in Table Bay Harbor, Cape Town. In: Johnson JW (ed) Proceedings of 4th Coastal Engineering Conference, October 1953, Chicago, Illinois , pp 52-78

Wilson BW (1954) Generation of long-period seiches in Table Bay, Cape Town, by barometric oscillations. Eos 35:733-746

Wilson BW (1976) Effects of long period waves in harbours. Alfred E. Snape Memorial lecture 1975. The Civil Engineer in S Afr 18:1-15 Woodborne MW (1983) Bathymetry, solid geology and Quaternary sedimentology of Table Bay. Bsc Thesis, University of Cape Town, Marine Geoscience Unit, Technical Report 14:266-277
Wübber C, Krauss W (1979) The two-dimensional seiches of the Baltic Sea. Oceanol Acta 2:435-446

Yasso WE (1965) Plan geometry of headland bay beaches. J Geol $73: 702-714$

Publisher's note Springer Nature remains neutral with regard to jurisdictional claims in published maps and institutional affiliations. 